\title{
READING, INTERPRETATION, REINSCRIPTION: THREE PERSPECTIVES ON ENGAGING WITH TEXTS
}

\author{
Douglas G Lawrie \\ Department of Religion and Theology \\ University of the Western Cape
}

\section{Introduction}

When one tries to describe what happens when people engage with texts, problems of terminology inevitably arise, not only because technical terms proliferate, but also because the ordinary, basic terms are used in different senses and with different intentions in various theories. It is probably by now beyond the power of any scholar or school to impose a uniform terminology. People, having invested heavily in their terminologies, do not abandon them easily (cf Burke 1966:19). Terms, one could argue, are merely tools, yet when it is a matter of coming to terms with our world, changing tools is no light matter. A world fashioned by means of a different set of tools would be a different world. Or, in Kenneth Burke's terminology, a different terminological screen would obscure some of the trusted old verities and reveal disconcerting new ones (Burke 1966:45ff).

In a game things are different: one can suspend one's world for the sake of the play. Similarly academics, whose game is argumentation, can, temporarily, accept a new terminology - for argument's sake. In suggesting the outline of a terminology for engaging with texts, I wish to propose a game, not impose a terminology. The purpose of the game is not to discover what interpretation (or some other term) "really means" or what "really happens" when we read, but to examine quizzically the different ways in which we talk about our acts of interpretation, to show why and where differences arise. In Burke's terms, it is thus a logical game (see Burke 1970:1-5), a game concerned with the terms we use to describe our motivations (Burke 1952:xf). When terms are defined in a particular way here, it is not denied that the same terms may be used in different ways in other discourses. In an analogous way, one may say that a knight in chess has these moves and that the piece moving in this way is called a knight in English, without denying that the term knight may be employed in other contexts and that the piece moving in this way can be called "ein Springer" in German.

\section{Presuppositions and aims of the game}

i) I presuppose that no theory is or can be fully adequate to what we call "reading", "interpretation" or "writing". To draw from this theoretical conclusions about "the impossibility of reading" borders on the hysterical ${ }^{1}$. Both logic and grammar permit us to say that our practice is better than our theory. Even in theory we can go beyond a reverent recognition of the ultimate mystery. To claim that one can give some account of where, when and why theory founders is not to claim that the mystery has been mastered. Some theoretical constructs will provide a more adequate account than others

1. This view is particularly associated with the work of Paul de Man. See, for instance, de Man 1979:76f, Miller 1987:121f and the critical discussion in Righter 1994:134ff. My point here is that the paradoxes, antinomies and aporias of language identified by poststructuralists can be dealt with (not disposed of) in a completely different mode. They are, to my mind, best approached with the "quizzical" attitude of Kenneth Burke (cf Burke 1952:x, 441f). 
do. This game is intended to serve as a tool for assessing and gainsaying theoretical constructs.

ii) None would deny that the process of dealing with texts is a complex one. Some complexities may be clarified by analysis into "steps", "components" or interacting parts. In this case the process is complex in the way in which a Freudian complex is complex. When one focuses sharply on one aspect of the Oedipus complex, say the hatred of the father, one necessarily loses sight of another aspect, the love and admiration for the father. Yet the love for the father is not an intrusion from another psychic context; it is intrinsic to the Oedipus complex and to the behaviour that arises from it. Therefore one cannot give an adequate account of the hatred of the father before moving on to the love for the father as a second component. The hatred and the love can each be explained only in terms of the other.

I presuppose that the study of what goes on when people engage with texts requires a periodic shifting of perspectives and not a detailed, systematic analysis that covers the field bit by bit. When sophisticated theoretical tools are used to sharpen the focus on one aspect, the result is a thoroughly deceptive clarity. Normally a perspective involves a limited effort of focusing that does not quite eliminate the blurs at the edges of the field of vision. It is easy to refocus, but then what had been at the periphery becomes central and the previous centre becomes a blurred margin. My contention is that the blur is an integral part of the picture. ${ }^{2}$

iii) It follows that in this game there can be no single correct answer to the question "How must we account for (describe) the process of engaging with texts?" Different perspectives are both possible and required. The perspectives discussed below cannot simply be added to one another to give "the full picture". In some respects each perspective is absolute and obscures precisely that which appears self-evident from other perspectives. On the other hand, none of the perspectives can, without distortion, be defended in its own terms. Each perspective generates a terminology that seems selfsufficient at a glance, but does not close on itself. If stretched to the limit, each terminology yields internal contradictions. Theorists sometimes try to take out insurance against this by saying that other theories are subject to internal contradictions whereas theirs reveal the inherent paradox of reading (or interpretation). I call this rhetorical strategy "Abandon your contradiction and accept my paradox". 3

iv) The play of perspectives is one factor that imposes a limit on theoretical constructs; another is the ethical horizon that appears within each perspective. Is it not strange that the more everyone is convinced that it is impossible to prove that one reading is better than another, the more is written about the ethics of reading (or interpretation) $?^{4}$ Having waived the right to judge in what used to be called matters of fact, critics

2. Actually, the metaphor I have used here is inadequate and hints at the problem that attends all attempts to represent a process in spatial terms (by means of "mapping", for instance). Such projects tend to suggest (often tacitly) that their representations are inadequate only in as far as they are incomplete. At least in theory, a series of shifts in perspective should finally provide "the whole picture", adding detail without disturbing the outlines already drawn. But if "what is not yet accounted for" is not a particular "space" (a temporary blur) but a particular action or motive force (a constant blurring), matters are different. Accounting for an additional factor may involve rewriting the previous account from scratch.

3. Thus Culler (1981:41) speaks of "paradoxes and undecidables" that the semiotic view "discloses as the unavoidable bases of language and thought" (my emphasis).

4. To take some random examples: Miller 1987; Docherty 1987:21-36; Scholes 1989: 89-155; Smit 1990a \& 1990b; The Bible and Culture Collective 1995:57-66; Earnshaw 1996:82-104; Steele 1997: 62-107. Steele (1997:1) says the bibliography on the topic is "staggering". 
(etymologically they remain judges!) now hasten to make moral judgements, that is, judgments previously deemed unscholarly. Although I do not hold that all sorts of judgements belong to the same order or that everything we do is automatically a subject for ethical debate, I shall try to indicate why "correct" and "morally responsible" cannot be conveniently separated in this case.

\section{Two sets of distinctions}

What happens when we engage with texts? What word best captures the action and what does the action entails? This is the primary set of questions addressed here, but it can hardly be separated from another set of question. How do the events take place? This question would not be needed if it were sufficient to say only that this or that has or has not happened. When it comes to reading and interpretation, however, one has to account for different outcomes. Clearly the acts of reading and interpretation are modified in certain ways, so that the acts do not produce predictable results. What are these modifications and why do they not inevitably shape each act of reading and interpretation in the same way? To tackle both sets of questions, two sets of distinctions are needed.

As for the first set of questions, one can distinguish three perspectives on what happens:

i) The perspective of reading focuses on receptivity and is linked to the terms factuality and reality. The ethical horizon of this perspective is mapped by the dialectic between accommodation and acceptance.

ii) The perspective of interpretation focuses on creativity and is linked to the terms fiction and actuality. The ethical horizon of this perspective is mapped by the dialectic between responsibility and responsiveness.

iii) The perspective of reinscription focuses on transitivity and is linked to the terms factitiousness and textuality. The ethical horizon of this perspective is mapped by the dialectic between integrity and relativity.

These three perspectives are supplementary (in Derrida's sense) and any one may be used metonymically for the others as a matter of tactics.

As for the second set of questions, one can distinguish four broad levels at which we engage with texts (answering the question how). In what follows I will use the perspective of reading as example, though the perspective of interpretation would do as well. The perspective of reinscription raises difficulties that require separate treatment. The four levels are:

i) The level of reading "degree zero" is the imaginary level of primary enabling.

ii) The level of competent reading is the level of operative ability.

iii) The level of specialized reading is the level of critical enablednesss.

iv) The level of reading "degree infinity" is the imaginary level of ultimate enabling.

The first and last levels are "imaginary" in that one cannot identify concrete instances of them. These are interacting levels and any one may be used metaphorically for the others as a matter of strategy.

Although this essay is primarily concerned with the supplementary perspectives, I shall deal briefly with the interacting levels, because the "how" can easily become confused with a "what". When one studies "dealing with texts" at the hand of examples, it is easy to conclude that some outcome has to be a product of "the process of interpretation (or reading) in general", whereas it may be a modification imposed by contingent circumstances. I shall first explain in general terms what I mean by the three supplementary levels, then say something about the interacting 
http://scriptura.journals.ac.za/

Reading, interpretation, reinscription: three perspectives on engaging with texts

levels, and then return to the supplementary perspectives to examine their ethical horizons. Lastly, I shall indicate why I believe that the game I am proposing casts doubt on the project of studying "interpretation" by examining interpretations.

\section{The supplementary perspectives}

The idea that the process of engaging with a text can be subdivided into stages or components is anything but new. Indeed, the metaphor of "mapping", when applied to interpretation, presupposes that the process called "interpretation" is internally differentiated in that it has "steps", "boundaries" or "factors" within it. Some of the schemata produced along these lines are without doubt useful and a number of them bear a certain resemblance to the one I am proposing. ${ }^{5}$ My notion of internal differentiation is not, however, based on steps in temporal succession, boundaries marking distinct "spaces" or factors in the quasi-mathematical sense. Each of the three perspectives covers the process of engaging with the text completely - temporally, "spatially" and operationally. ${ }^{6}$ When one looks at the process from the one perspective, the others virtually disappear from view - they become a blur at the edge. In other words, in covering the whole process, each perspective also covers (effaces) the rival perspectives.

The following example can illustrate what I mean. In critical debates about "the role of the reader" the question was often asked: "Do texts or readers produce meaning?" As Andrew Bennett (1995:3) puts it, the debate was about the location of meaning. Bennett goes on to distinguish between those who relate meaning substantially to the individual reader, those who relate it substantially to textual structures and those who, as it were, divide up the spoils (1995:4). These seem to be the only logical possibilities. Now it is easy enough to argue that no text has, of itself, the authority to impose any reading on me. The moment someone suggests to me that a particular sentence can be read in only one way, I could demonstrate the opposite by wilfully imposing an idiosyncratic reading on it. With some ingenuity, I could even make my folly interesting, if not plausible. For all that, I may also believe (and teach students) that the two texts "The man bit the dog" and "The dog bit the man" impose different readings through their syntactic structures. Even more tellingly, I would act as though certain texts produced by me should be clear and unambiguous to those I address. In the one case, dealing with a text is entirely and "obviously" an activity of the reader, the text being no more than the "site" that "instantiated" the activity. In the other case, dealing with a text is entirely and "obviously" controlled by the structures and codes of the text, ${ }^{7}$ the reader being no more than the "site" of decoding and pattern recognition. Both views make sense.

5. For instance, Harold Bloom's theory of the three revisionary ratios (Bloom 1975: 84-105), Robert Scholes's distinction between reading, interpretation and criticism (Scholes 1985:21-24) and Seitz's three "moments" in the reading process (Seitz 1992:147) all bear a distinct resemblance to my scheme, but there are other examples as well. In the simplest terms, it makes sense to say that something taken from the text (receptivity) is reworked (creativity) and thereby given a new shape (transitivity). Thus Jauss uses the quite traditional distinction between intellegere, interpretare and applicare in roughly this way (cf Newton 1990:134).

6. It is in this vein that Culler (1983:76) remarks that for the reader the text is "already complete and inexhaustible" and, simultaneously, "still to be created in the process of reading". See also Culler (1981:39).

7. Such a view is often confused with one that insists that texts have a univocal meaning. That this view can accommodate polysemy, ambiguity and even undecidability is clear from the writings of both the New Critics and some structuralists. See, for instance, Cleanth Brooks's essay "The Heresy of Paraphrase" (Brooks 1968:157-175) and Abrams 1991:125f. Nor is this position fundamentally changed by introducing notions of intertext and social convention. These too reach the reader as texts and can influence the reader only in as much as they - as texts - exercise authority over the reader. 
I have found Derrida's notion of supplementarity useful in this regard. ${ }^{8}$ A supplement, Derrida explains, can be seen in two ways. In one sense it is "a surplus, a plenitude enriching another plenitude, the fullest measure of presence." The question, of course, is why a plenitude, which should be self-sufficient, should need any supplementation. In the other sense, a supplement replaces or represents. Representation implies "the anterior default of a presence." It is a sign that fills a gap or takes a place that is or has become empty. (Derrida 1992: 83). Each of these two senses "is by turns effaced or becomes discreetly vague in the presence of the other. But their common function is shown by this: whether it adds or substitutes itself, the supplement is exterior, outside of the positivity to which it is super-added, alien to that which, in order to be replaced by it, must be other than it." (1992:84). The supplement is thus distinguished from the complement, which may be seen as an added "factor", "step" or "element" that merely completes the picture. The supplement is an affront to "nature", since nature should by definition be self-sufficient, and to reason, which insists on clear-cut identities and oppositions (1992:89). But the supplement is like différence in that it undermines notions of identity and the opposition between presence and absence (cf 1992:89).

I appropriate (or misappropriate ${ }^{9}$ ) Derrida's notion of a logic of supplementarity in the following way: Texts in and of themselves are replete with meaning: meaning (but not a single univocal meaning) is always already inscribed in texts. Yet a text requires a small, apparently contingent supplement - a reader. As long as the perspective of the text is held, the reader is no more than a mediator of what the text is - a sign, an embodiment or a marker. One can even say that the reader is an extension of the text. But an equally valid perspective would insist that texts are constituted or "written" by readers. The creative activity of the reader attaches itself to a text, which is a supplement to what is already fully present. The text, after all, merely provides the words (signs), whereas the reader provides the meaning. In each case the supplement turns out to be less harmless than it had seemed at first glance. The supplement, instead of being a mere gloss on an original full presence, comes to signify (represent) the presence, thereby signalling its absence. Texts have no "original presence" apart from readers, but neither have readers "originality" apart from texts. The conception of origin is permanently destabilized. As a result of this, it is inappropriate to ask what "part" of meaning comes from the reader and what "part" from the text.

In my simpler terminology I have spoken of receptivity and creativity. The temptation is to see these as ordered in a temporal sequence, as if one first receives from the text (reading) and then creates meaning from the data (interpretation). Yet one could as easily argue that reception depends on a (prior) "making an ear for" as one could say that creation depends on (prior) reception of material that has to be shaped.

Receptivity and creativity, though they cannot be separated temporally or "spatially", are structured in different ways. The receptive - what I call reading - is orientated towards that which precedes the reader's engagement with the text, that which is factual in the sense of "having been made". The facta of the texts confronts the reader as res, that is, things that have a reality structure. It is probably necessary - though tedious - to say that ideologies, myths, fictions, lies and social constructs are all realities in this sense. Indeed, whatever evokes resistance, subversion, demystification or counter-reading has already been tacitly

8. Derrida introduced this notion in Of Grammatology. The section on the supplement and many other important texts by Derrida are now conveniently available in Attridge's collection (Derrida 1992), from which I shall cite.

9. Let us, sticking to a Derridean terminology, say that my use is a "graft" on the text (see Derrida 1992: 153ff). 
taken as a reality. But the same goes for that which elicits respect, commendation or support.

Interpretation is not the complement of reading, that is, the completion of the process initiated by reading. It consistently "fictions" (manufactures) its own object just as much as reading consistently takes its object as a fact. Whatever has not passed through the fictioning process of interpretation is not an actuality for the reader, but merely a potentiality. Sometimes interpretation passes through stages of actualization or successive fictions. I may, for instance, interpret an approaching figure first as a person, then as a woman, then as Margaret, and finally as someone who looks like Margaret but is not Margaret. The point is that at one stage I actually saw Margaret, though the Margaret I saw turned out to be a fiction I produced. In principle, of course, the "final instance of interpretation" is no less fictional that previous instances. Every actualization remains open to revision.

It is tempting to see receptive reading and creative interpretation as binary opposites and to talk of a dialectic or a field of interaction between the two poles. This would, however, obscure the logic of supplementarity that links them. In a finicky mood I would insist that there is no interaction between reading and interpretation, but only, in a complex sense, a conversation. The one is the converse (opposite) of the other, yet it also is the other converted into a representation. Each tries to convert (change, proselytize) the other to its terms. By introducing a third term, reinscription, I avoid a simplistic bipolar view, but invite another understanding that runs counter to my notion of supplementarity. It is all too easy to see reinscription as a Hegelian Aufhebung of receptivity and creativity or at least a site from which the two can be viewed synoptically. Indeed, I believe that some theorists "overcome" the problems of engaging with texts in this way. ${ }^{10}$

In dealing with a text, a reader does not only receive and create, but also sets in place a new entity - an interpretation or reading. This entity is in principle public in that it is cast in the communal language. Admittedly, the reinscription does not have to be either in writing or in overt speech. In one case I may ask, "How can I convey my understanding of the text to you?" In another case I may ask: "How can I clarify to myself what I perceive here?" 11 In both cases, however, it is a matter of producing something that addresses an audience: the second case is a specialized form of the first. In both cases a text is re-textualized: "In a sense, all texts undergo a process of re-writing as they are re-read, re-produced; reading and interpretation could ... be thought of as re-inscription" (Webster 1990: 99). ${ }^{12}$

In a way reinscription can be said to "come after" reading and interpretation. The paradigmatic case seems to occur when a reader (interpreter) "finally" produces a written interpretation (reading). But reinscription is closely related to intertextuality (see Webster 1990: 97ff) and intertextuality is operative from the moment one begins to engage with a text. From the very beginning we "make something of" a text "in terms of" other texts and literary conventions that precede both reception and creative activity. Of course, as reading and interpretation goes on, every reinscription is overwritten many times. The point here is

10. See, for instance, Walter Benn Michaels's attempt to overcome the subjective-objective split (Michaels 1980: 199f).

11. Barthes (quoted in Scholes 1989:49) said that we rewrite "the text of the work within the text of our lives." Similarly, Jauss (quoted in Newton 1990:134) says that application involves "transporting the text out of its past or foreignness and into the interpreter's present".

12. Or more simply: "The response to a text is itself always a text" (Scholes 1985:20). 
that the perspective of reinscription effaces the free creativity of the interpreter and the authority with which texts seem to structure their reception ${ }^{13}$.

The perspective of reinscription remains extremely difficult to describe adequately. It tries to capture how "dealing with a text" is both a revival and a replacement of the text, how the very "representation" of a text in reading or interpretation marks a transition from the text to a new text ${ }^{14}$. Since what has to be the point of focus is a movement, the perspective is perpetually somewhat out of focus. From a textualist position one can say that reading or interpretation adds to textuality or spins out the web of the text, that entering the labyrinth leads to no exit but expands the labyrinth itself. From a contextualist position one can say that the reception of a text - in what is always inevitably a new context restructures the field of reception of the text ${ }^{15}$. As metaphor for the transition one can invoke the dialectic of transference and counter-transference, as LaCapra (1989: 36ff) does in discussing the work of the historian. It is, in any case, important to note that there is a "double movement". It is not simply the transition of the text to a new context, nor simply a displacement of the text by a new text. Any "knowledge" gained from this perspective has to be called a "double science" in the Derridean sense (cf Derrida 1992: 133ff; Culler 1981:43).

The difficulty of this perspective can be described as follows: On the one hand "the text" is too distant to allow a normal focus; on the other "the field of reception" is too close (we are part of it). What is "seen" is always neither this nor that, but traces of what had been both this and that. The perspective positively invites postmodern terminology. One can, in view of the textualization of any reading or interpretation, use the terminology of the web or network (there is no hors texte), but one can also, in view of the impossibility of gaining an overview, employ the terminology of absence, fissure or difference. One can, in the fashion of Derrida, interrogate the "trans" of "transition", noting that it can signal either a passage across that links two parts or a beyond that leaves the point of departure behind. That this particular perspective gives rise to all sorts of preciousness and posturing signals, I believe, that it is a perspective that remains nearly completely blurred. Nothing gives rise to as much portentous rhetoric as ignorance that falls just short of being total.

My own little contribution to this Babel is the word "factitiousness", which I employ to say simultaneously that in reinscription a new "made thing" appears and that this "made thing" is not the spontaneous or natural ("organic") product of either the text or the creative ability of the reader. The reinscribed text, however artistic, is artificial and even deceptive with respect to both the text and its reader. What results from reinscription is not the reality of the text and it is not actuality of or for the reader - it is textuality, anew open to the vicissitudes of texts. It can, for instance, assume priority over the text of which it is the reinscription when someone reads the text with its reinscription as intertext. It can be recreated in a way that decreates the sense made by the previous reader.

Each perspective covers the others in the sense that it hides them. To make a particular point (tactically), one may use one of these perspectives by way of metonymy for "dealing

13. The first point, which is easier to grasp, can be turned against, for instance, David Bleich. The second point works against Stanley Fish once one sees that his "interpretive communities" are pre-texts endowed with absolute textual authority.

14. Thus Derrida speaks of a reading that assumes "the form of another writing, in a text in transformation in which the possibilities of differential play are increasing and at the same time becoming increasingly determined" (1988:147).

15. On the (tenuous) distinction between contextualist and textualists, see Felperin 1985: 29ff. Earnshaw (1996 and passim) uses extrinsic and intrinsic in this regard. 
with texts" (as the broader category). The metonymy then (temporarily) displaces the other perspectives. But should one insist that the metonymy cover all the perspectives in the sense of does justice to them all, the metonymy becomes reductionist. ${ }^{16}$

\section{The interacting levels}

The different levels do not efface one another. Indeed, nothing prevents one from using one of them as a lens through which the others can be seen. For instance, a highly specialized interpretation may be seen as an elaboration of very basic competencies and a simplistic reading may be regarded as exhibiting a lack in relation to a specialized one. To impose one term as a guiding metaphor (perspective) does not imply losing sight of the others and can constitute a fruitful strategy.

The use of the term "levels" suggests grading, but these levels need not be viewed hierarchically. One can construct two (or three) different pictures of them: a hierarchic one and a centripetal/centrifugal one. In the first case, the picture is of four steps. Reading "improves" as one moves from the first to the fourth step. Note, however, that the first and fourth steps represent imaginary levels: they are theoretical constructs and no act of reading can be placed there. Reading degree zero ${ }^{17}$ represents reading with the bare essentials that enable reading in the first place (primary enabling). Below this minimum level no reading at all is possible. Of course no actual reader ever approaches a text with these bare essentials. The actual reader always has competencies in excess of the minimum requirements - there is always already icing on the cake. ${ }^{18}$ Similarly, reading degree infinity represents reading taken to the ultimate, in that nothing that could enable (better) reading is lacking (ultimate enabling). At this level reading involves a purely theoretical plenitude of competencies. No actual reader can respond to all imaginable cues offered by a text, nor can theory circumscribe the competencies that would be involved except in a vague, uninformative way. In practice, the first step is always an imaginary point of departure and the last step an equally imaginary destination.

At the level of competent reading, readers feel that reading is a skill they have by and large mastered. They are unlikely to ask exactly what distinct competencies go into an individual act of reading and how these competencies were acquired. They are more inclined to think of reading as something they can do (operative ability). If they fail to demonstrate their normal competence in an individual case, it does not usually lead to serious doubts about their competence: "This book is difficult." Specialized reading differs from competent reading mainly in that specialized readers, more or less consciously, apply internal differentiation to the term "reading". For instance, they may say that different genres need to be read in different ways, that the Bible can be read as literature or as a guide to life, or that there are different methods one can use in reading. The single trunk "reading" has, for them, sprouted specialized branches. Moreover, the critical distinctions made by specialized readers depend on specialized teaching that builds on general literacy. Specialized readers have been critically enabled.

16. For the link between metonymy and reduction, see Burke (1952:506ff).

17. The qualification "degree zero" is borrowed from Roland Barthes, who spoke of "writing degree zero" to describe a form of writing devoid of all conventions, style or ideology. Obviously this is a purely ideal construct (cf Felperin 1985:80f).

18. In a sense the minimum requirement, which may be called the ability to respond to signs, is purely formal, whereas the competence to respond to any particular sign is always contingent. 
Where the individual reader is placed on these steps is not a matter of academic interest only. The hierarchy in this picture marks itself socially in as much as graded levels of ability are ascribed to various readers or groups of readers. Whether a person is described as "barely able to read" (just above step one), "quite competent at reading" (on step two), "able to read specialized academic texts" (on step three) or "a superb reader" (approaching step four) matters greatly in practice.

The other way of envisaging the levels embraces two subdivisions (centripetal and centrifugal), but the same picture can serve as visual model for both. It is a picture of three concentric circles around a central point. Every act of reading may be thought of as a movement from the centre, the bare basics of reading, through general competencies to more specialized ones, always tending towards the outer limit, the ultimate reading. This is the centrifugal view of the picture. In the centripetal view, reading moves from the periphery as basic minimum, through the inevitable "specialization" imposed by the context of the individual reader, to a level of general competence, tending towards a centre of universality. ${ }^{19}$

Whichever way this picture is viewed, it suggests that all reading inevitably involve all the levels. The levels are present as "moments" in the movement of reading itself and are not levels attained by different readers. Notably, "specialized" is not regarded as better than "competent". If the picture is viewed centrifugally, every specialized reading is rooted in a competence to read - it is a refinement of the prior competence. If the picture is viewed centripetally, every competent reading is rooted in an already specialized approach (depending on "context" or "interest") - it is a broadening of the narrow focus of the given specialization. Moreover, degree zero and degree infinity are to some extent interchangeable. At most the movement from the one to the other signals something like a Hegelian coming to self-consciousness. In the hierarchical picture "degree zero" signals the imaginary level of the "always already" and "degree infinity" the imaginary level of the "always not yet". In this picture the distinction is tenuous - what primarily enables reading is what ultimately enables reading. What comes between the two is no more than the explication of implications. One could therefore say that "degree zero" and "degree infinity" stand at both the centre and the periphery of the circles.

The two pictures seem to picture quite different things, yet they contaminate each other. The hierarchical picture presents us with graded levels, but one is often tempted to say of a highly technical, specialized reading that it involves, for all its critical and theoretical finesse, a lack of competence at simple reading. The specialist has failed to see the wood for the trees. Equally, a competent reading (by an "untrained" reader) may involve a "secondary" aspect of specialization that amounts to a specialized "reading strategy". The advantage of the trained reader may in this case lie in her or his ability to recognize that this strategy is not the only available one. On examination, the distinction between the implicit strategy and the explicit, self-consciously "theoretical" one may prove to be mainly terminological. That academics manage to communicate in writing in spite of the proliferation of conflicting theories of reading suggests that at least some of us make do with implicit reading strategies that are at odds with the critical ones we champion in theory. Such reflections have the effect of calling into question the social inscription of any particular gradation.

19. I have borrowed the idea of the centrifugal and centripetal movements in reading from Robert Scholes (1989:8f), who used it in a different way. 
When one views reading as a centripetal or centrifugal movement, one looks at what takes place ("inevitably") in any act of reading. Should one be tempted to say that specialized reading "goes beyond" competent reading, having adopted the centrifugal view, one can simply switch to the centripetal view and aver that competent reading goes beyond mere specialization. ${ }^{20}$ But it is hard to banish hierarchy completely. For instance, all readings are in an obvious way "contextual", yet many would claim that their readings are contextual in a way that other readings are not and that there is some virtue in this. Academics, in particular, cannot afford to be too strident about false hierarchies (as opposed to true equality?) imposed by the wicked or the foolish (or by impersonal structures). In the first place they claim to have read the situation better than others have, and in the second place they grade papers. The notion of graded competence is entrenched in their theory and their practice. The last-ditch attempt to get rid of hierarchy via a theory of the inevitability of misreading has not had much success. Somehow the hierarchy is reinstated - by introducing a distinction between strong and weak misreadings, for instance (but Bloom, whose terminology I borrow, is by no means averse to hierarchy ${ }^{21}$ ). Such reflections have the effect of calling into question the "inevitabilities" of theory.

What shall we say then? That dealing with texts in a particular way is conditioned (modified) by basic processes (moves, conventions, strategies) and by contingent mixtures of knowledge and ignorance? Cannot this sign of ignorance be, instead, the sign of a specialized knowledge beyond the grasp of the interpreter of interpretation? As long as we stick with broad categories, we may believe that we are finding out how women read by examining the readings of women, but a particular woman may be reading from a different "specialization". An example from my experience illustrates how the interpreter of interpretation may err. A (black) student wrote to me in an assignment that the prophet Amos was a black man. What a marvellous example of creative interpretation, recalling the extended meaning given to "black" by Cone and others! This, surely, was how the student "bridged the gap" between the context of Amos and her context. This is what I thought until I had read the same statement, surrounded by similar phrases, in other assignments. After that it proved easy to find the commentary in which Amos is described as "a native of Tekoa". In any case, any theory of "interpretation" that blinds itself to the effects of common or garden ignorance - including the specialized ignorance of the specialist ${ }^{22}$ - and to the human propensity to err even when error is avertable is unlikely to have much to tell us. What is even more disturbing is that it is not easy to say whose the ignorance or the error is.

20. There are also political considerations (the discourse on the levels being "political" just as that on the perspectives is "ethical"). For instance, the centrifugal view could suggest that a feminist reading is merely a (disseminated) specialism grounded in a purportedly general competence, which may actually be a male construct (see Schweickart 1995:81ff). But the centripetal view could suggest a woman's reading is grounded in an essential (non-contingent) femininity, a "female nature". The result would be "the mutual illegibility between genders" (Dimock 1995:123) that leaves the feminist view locked in the female community. Although I have not thematized the political aspects in this article, I have certainly not overlooked them.

21. Recently, Bloom has made this quite clear. What "is to be done" (in training readers) involves "some version of elitism, and that is now unacceptable, for reasons both good and bad" (Bloom 2000: 23). "Misreading" was a term used for a specific purpose and it was frequently misread in a more mundane sense of the word (2000: 25$)$.

22. Bertrand Russell (quoted in Scholes 1985:86) ridicules "some modern philosophers" who claim that "the cat is a carnivorous animal" does not mean "that actual cats eat actual meat, but only that in zoology books the cat is classified among carnivora." He concludes: "This is one of those views which are so absurd that only very learned men could possibly adopt them." Burke (1935: 14ff) borrows and expands Veblen's concept of "trained incapacity" in this regard. 


\section{The ethical horizons of the complementary perspectives}

Each of the three perspectives has an ethical horizon against which the whole process (as seen from this perspective) can be evaluated. The horizon can be expressed in terms of a pair of ethical terms, of which the first corresponds roughly to the category of personal ethics and the second roughly to that of social ethics. The terms of each pair are neither inherently complementary (and - and) nor intrinsically contradictory (or - or). Instead, each pair sets up a flux of mutual subversion and reinstatement, signalling continually and simultaneously their mutual incompatibility and their mutual dependence.

In reading, the agent as reader has to be an accommodating person (personal category) and has to accept the otherness of the other (social category). An otherness that is not in some way accommodated remains an "unreadable" otherness that is, at least in that sense, unaccepted and unacceptable. ${ }^{23}$ On the other hand, "the need to be an accommodating person" simultaneously and tacitly signals that acceptance is not fully "present" and can only be "represented" (in its absence) as a temporal and temporary act of accommodation. Since this is an act of the reader, it involves accepting the other only on and in the terms set by the reader - the other is naturalized as "non-other", as that for which room has been made/found. At the same time the claim of "what is read" (text/author) to be accepted (given a hearing, taken on its own merit) denies the ethical validity of solutions based on letting otherness stand as unreadability. What is read offers itself as address - to deny this is to adopt a position that is not to be distinguished from solipsism in practice. ${ }^{24}$ The ethical claim on the reader's regard ${ }^{25}$ or attention presupposes an ability to accommodate and a merit (or gain) in accommodating precisely that which presents itself as other. This is the urgency of address. Nevertheless, the same ethical claim resists any given accommodation as a makeshift in which it refuses to be at home.

The ethics of reading confronts the reader with "facts" that are not - at least not simply products of her own "fictioning" or with a "real" that is not a result of reification. I introduce these two suspect terms, because I am convinced that these terms are indispensable to an ethics that takes differences seriously (as opposed to an ethics that talks seriously or playfully about difference). A theory of dealing with texts that reduces the perspective of reading as receptivity to one or both of the other perspectives may claim that it avoids the reification of the other; it generally goes to the other extreme and spiritualizes the other (cf Scholes 1985:93f). The objection that the terms "fact" and "real" have served (in so-called foundationalism) to stabilize coercive structures depends on a shift of perspective - towards the perspective of reinscription. Eliminating them from the perspective of reading removes the "real" appeal of the other and leaves the other nothing but the mystique of otherness.

Facing the other as a real other and otherness as fact that I cannot fiction away calls for accommodation and acceptance. The two terms validate each other as value terms, yet each is undermined as a value concept by the other.

23. Earnshaw, using Buber's terminology, argues that positing too radical an "otherness" replaces the I-Thou with the I-It relationship, because the other is reified as "the Obscure" (1996:125). In the same vein, Steele (1997:6) talks of an "indiscriminate appeal to diversity" that provides no positive language in which to discuss the identities and traditions of oppressed others.

24. Normally solipsism is regarded as the ontological theory that states that nothing except the individual subject exists (see Schmidt \& Schischkoff 1965: 554). But theories that question radically the possibility of effective communication reach roughly the same point.

25. Miller (1987:15ff) plays merrily and expertly with Kant's term Achtung, which has something of the same ambiguity as "regard". 
The ethics of interpretation requires an interpreter who acts as a responsible agent, that is, somebody who shoulders the responsibility for what he or she has created in the act of interpreting. ${ }^{26}$ The interpreter is open to the charge of acting randomly or whimsically precisely when the given interpretation cannot be defended as an interpretation that is responsive to the text. On the other hand, the claim that an interpretation is fully responsive to the text (and its various intertexts) disclaims responsibility. Thus the interpretation that is not responsive is not a responsible interpretation, being an idiosyncratic or egoistic one, but the interpretation that is fully and merely responsive denies responsibility (cf Miller 1987:4). The conception of responsiveness positively demands a responsible interpreter, yet it also undermines the independence of the interpreter that would make the interpreter a responsible agent.

Just as the struggle with the ethics of reading as receptivity can lead to the desperate denial that anything is there to be received (solipsism), so the struggle with the ethics of interpretation as creativity can lead to the desperate denial that the interpreter is able to create anything (determinism). For instance, the interpreter in Stanley Fish's theory is neither an independent, responsible agent nor is she or he responsive to the text. Interpretations, however, are not random, since they are (always already) determined by the "interpretive community". ${ }^{27}$ When the perspective of interpretation as creativity is reduced to the perspective of reading as receptivity, interpretation becomes a reproduction of existing meaning.

The ethical horizon of the perspective of reinscription is mapped by the interplay between integrity (or integration) and relativity. The perspective is complicated because both terms may be viewed either "theoretically" or "personally" (here I mean, "pertaining to persons", not "pertaining to the individual"). From a lofty theoretical perch one can discuss integrity and relativity as aspects of the text, noting how every reinscription remains caught between framing (integrity) and intertext (relativity). On the one hand no frame imposed on the text can capture it as an integrated whole; on the other hand the very assertion of relativity (that a text is related to an ultimately endless intertext) implies that reinscription is always a non-random process of integration. Reinscription both imposes and transgresses frames; it both relates and divorces. I suggest that, in Derridean fashion, one could look at the "de-" and the "con-" of deconstruction as the mise en abîme of the whole theoretical construct (cf Derrida 1988:159 n13).

If one turns to the personal aspect of the same dialectic, one can argue that integrity and relativity are, as one can expect within the perspective on dealing with texts that is most rigorously "theoretical", the most general terms of ethical discourse, at the personal and social levels respectively. To rephrase, the problem of personal ethics is the problem of the integrity of the ethical agent and the problem of social ethics is the problem of relativity to or relationships with others. The ethical problem of reinscription is, I believe, misunderstood if it is formulated in the Kantian terms of autonomy and heteronomy (the

26. Jane Tompkins has noted that Stanley Fish makes moral claims for his position that "imply a self that is independent, free and responsible for its own choices". But, as she points out, Fish's theory denies that such selves exist (Tompkins 1980: xxiii).

27. See Fish 1980: 14, 172f and passim. Eagleton (1991:169) rightly calls Fish's position "iron determinism", though no doubt Fish would disagree. In my view, many praise and criticize Fish for all the wrong reasons, mainly because they overlook the radically conservative streak in it. Yet Fish makes his position perfectly plain in (for instance) Fish 1989:141-160; 343-355. Change is not denied, but rendered ineluctable., therefore whatever can be perceived (or done) is under the sign of "always already" (his favourite phrase). To expect Fish to "give moral justification" for his reading practices by adding a layer of ideological criticism (The Bible and Culture Collective 1995: 57) is to ask him to abandon his whole theory. 
Kantian approach would be at home in the perspective of interpretation) or in any of the terms of an ethics of rules (or law; see Miller 1987:127). For much the same reason, it leads to unnecessary confusion to gloss the integrity of the reinscribing person as the unity or centredness of the knowing subject. In as much as reinscription is always a way of relating, any integrity ascribed to the persons involved has to be a relative integrity, an integrity that comes into being in meeting. ${ }^{28}$ Nevertheless, meeting or relating is only possible if some form of provisional integrity is ascribed to the relata. Relativism, if embraced as an "ontological" theory (a theory about "what is the case"), spells the end of ethical discourse in as much as the integrity of the relata is then seen as a simple product of the network of relationships. Similarly, "substantialism" destroys ethical discourse by positing integrated substances of which the relationships are predetermined by the substantial integrity of the relata. $^{29}$

I take relativism (in a special sense) and substantialism as desperate attempts to deny transitivity, just as solipsism and determinism are desperate attempts to deny receptivity and creativity respectively. Relativism (in the special sense I am employing for this purpose) turns relationship into brute fact (the terms juxtaposition generally marks this type of relationship that is purely fortuitous). De Man's theory of allegories and of parallel "falls" provides a good example. There is no transition or passage between text and reinscription "in reality"; reinscription relates to text as word does to thing (that is, in a way that remains undecidable). Substantialism turns integrity into brute fact and simultaneously renders integrity ineffable. Any reinscription either is or isn't "substantially" the same as the text it is dealing with. ${ }^{30}$ The upshot is much the same in both cases.

The perspective of reinscription demands that the integrity of the person and the relationships within which the person stands are always to be performed or enacted anew. But the performance or act is not really "creative" since a script for the performance is already given. The script (text) is never the performance (enactment), yet the performance is always a performance of this script. The distinction between this perspective and that of creativity is rather like Austin's distinction between what one does "in saying something" and what one does "by saying something" (Austin 1975:121ff).

These reflections could very well end in a gesture of heroic despair. What ought to be (in the matter of dealing with texts) is precisely what can never be. Being doomed to read (interpret, reinscribe), we are also doomed to do so badly. In short, we are in a situation of non posse non peccare. This is more or less the position that Hillis Miller reaches in his Ethics of Reading ${ }^{31}$ - a position ridiculed with savage justice by Robert Scholes

28. On the point of human persons, a Christian ethics of reading (etc) has to part ways with most poststructuralist ethics, as Watson (1994:103ff) rightly points out. Concerning the "priority of human relatedness" "there can be no ... compromise" (105). Seyla Benhabib (1999:353ff) makes a similar point regarding the relationship of feminism to poststructuralism. Earshaw (1996) and Steele (1997) believe that literary theory itself cannot do without a richer language of personhood.

29. It is to the credit of Kant that he introduced the messy distinction between pure reason and practical reason. It would appear that Kant's arguments about autonomy and heteronomy lands him in the position of defending a form of ethical substantialism in which all ethical discourse is grounded in the autonomy, freedom and rationality of the ethical subject, in other words, in the integrity of the ethical subject. But Kant also adds that the ethical subject acts "as a member of the kingdom of ends" (1991: 95, 97). This makes his position less easy to typify. The ethical problem (of integrity and relativity) is not solved by introducing history as a vector (either in Hegelian fashion or otherwise). It does help to pose the problem more adequately.

30. The "heresy of paraphrase" in New Criticism was indeed a form of substantialism in that it denied that the substance of a poem could be expressed in any interpretation. This illustrates how "integrity" becomes ineffable in substantialism. The poem is "itself", but it is impossible to say what this "itself" is.

31. Crucial passages are Miller (1987:1-11; 33-39; 43-59; 120-127). 
http://scriptura.journals.ac.za/

(1989:145ff). Scholes rightly points out that Miller presents a perverse version of the Christian doctrine of the fall: the inevitability of guilt is there, but without either original free will or ultimate salvation (146).

It seems to me that one cannot escape from such aporetic conclusions as long as one remains - as Miller did and as I temporarily did - within the logic of textuality. ${ }^{32}$ Miller, following de Man, insists that he is examining ethics or, as de Man, puts it, "ethicity", as it appears "in the act of reading", that is, without reference to anything outside reading as purely linguistic activity. ${ }^{33}$ Similarly, I have spoken of the ethical horizon that appears within an act of dealing with a text. As long as this horizon remains an empty, formal structure, it necessarily constitutes a limit that serves only to remind me of my limitations.

But what if someone (or Someone) appears on the horizon and moves towards me? ? $^{34}$ What if I appeared to this someone as a someone on a barren horizon that offers no beyond? The mutuality of the dilemma may well be the resolution of the dilemma. For instance, the integrity that I cannot attain an sich (as ontic centre of action) or für sich (as self-conscious centre knowledge) is something I may enact with regard to another if the other willingly relates to me. Integrity is, one could say, imputed to me. It is not sufficient to say that I am called upon to be responsible, accommodating, and so on, because this call, since it may be said to issue from language, continues without a pause and leaves no gap for a determinate answer. What hope there may be, lies in a reciprocity that is not inherent in language. ${ }^{35} \mathrm{At}$ the most secular level, salvation is possible only if the word becomes flesh. This is why the project of "understanding understanding" leads either to impositions or to an ironic credo of ignorance.

\section{It may be gainsaid}

Why play along in this game? Can the three perspectives be applied to distinct acts of "dealing with a text", thus helping us to understand understanding better? Do people consciously and discretely read and interpret and reinscribe? I believe that people often do make a partial distinction, one that cannot be fully expounded or carried to conclusions. At times these distinctions, blurred as they are, may help in evaluating the performance of others. ${ }^{36}$ Because the distinctions are debatable, they can stimulate debate. But by and large

32. As opposed to ethical standards that regulate interpretation from the outside, as discussed by Smit (1990a \& 1990b).

33. According to de Man (1979:206), ethics has nothing to do with "the will (thwarted or free) of the subject, nor, a fortiori, with a relationship between subjects." Similarly, Miller (1987:1) assumes that anything "interpersonal" would not be "properly and independently ethical". But "ethical judgment and command is a necessary feature of human language" (46) and "it is impossible to get outside the limits of language by means of language" (59).

34. It has to be pointed out that this eventuality is not covered by talk about social ethics. A theory of social ethics, in as much as it is a theory, necessarily treats society as a network, a fabric, a text.

35. Conceivably Derrida (1992:342f) says something similar, for instance, when he talks of a "we" that does not invent itself: "It can be invented only by the other who says 'come' and to whom a response with another 'come' seems to me to be the only invention that is desirable and worthy of interest. The other is indeed what is not inventable, and it is the only invention in the world, the only invention of the world, our invention, the invention that invents $u s$." But I do not flatter myself that I understand either these sentences or the passage as a whole. In any case, my next sentence signals the end of my flirtation with Derrida.

36. Derrida provides an example in the long footnote in which he confronts some of his critics, notably Habermas (Derrida 1988:156ff). He complains that he has "quite simply ... not been read" (156) by Habermas, whom he challenges to prove "the presence [!] in my work" (157) of certain views. In part, then, Habermas is accused of "nonreading" (157), that is, a lack of receptivity. But Derrida also blames Habermas for daring to "intervene in, interpret, arbitrate, conclude" Derrida's debate with Searle, although he (Habermas) admits that 
the distinctions do not provide a reliable guide. In my terminology, reading is "of a text" (receptive), but, as academics of all people should know, texts are often partially or sketchily read. My "reading" of a text I have browsed through would be marked by a lack of receptivity, yet an observer could see it as a particular creativity with respect to the text in question. The creativity (and indeed of the receptivity) is there, but it does not pertain to the text in question. I certainly used "an interpretative strategy" to "bridge a gap". The gap, however, is between my ignorance of the text and the context in which I wish to hide this ignorance; it is not the gap between the text and my context. Similarly, the reinscription I produce, having received and created and rewritten to myself as audience, is and is not "mine" in the sense of being a summary record of my reception, creation and reinscriptions of the text. It is, more simply, what I offer this audience - to impress, instruct or deceive. And, in a far from simple way, this audience will impose its terms on it.

The problem with studying, say, "the interpretation of the Bible" by examining "interpretations of the Bible" is that one tends to substantialize both the Bible and the interpretation, turning them into foundational entities. "This is the Bible, which is substantially what is being interpreted - with the (secondary) aid of intertexts, tradition, interpretative strategies, and so on. And this is the interpretation, which is substantially the result of interpreting the Bible - with other processes contributing merely secondary characteristics." Why are we to believe this? Nor does it help to generalize interpretation, thereby desubstantializing everything. When the term interpretation becomes a blanket term, it does what blankets do - it hides everything from view, leaving only interpretation to be studied. "We no longer study to gain knowledge, because we now know that all knowledge is constructed in the act of interpretation. Instead, by studying interpretation, we examine the conditions of our knowledge, the mechanisms that determine what constitutes knowledge and what constitutes ignorance." (I have read such sentences more than once.) But since interpretation is everything, nothing less than everything will help us to understand interpretation. In the meantime we can only spin out words in the blind faith that somehow they bear witness to interpretation.

I propose instead that we stumble on, rather untheoretically, in a conversational world where statements, far from being undeniably witnesses to anything, can always be gainsaid. In fact, my three perspectives may be seen as a modest mechanism for gainsaying in that it can serve to generate replies to statements about "interpretation". "So this is how you interpret this text? How interesting." "No, this is not how I interpret it; it is how I chose to reinscribe it under these circumstances." "But surely you imply that this must be read in such a way?" "Frankly, I did not remember that part of the text at all. If I had, I might have changed my tune." "Still, by emphasizing this word rather than that one, you used a

the debate is "impenetrable" (157). Lack of receptivity is aggravated by excessive creativity. Moreover, Derrida blames Habermas for "abusing" citations (of Derrida) by Culler, where "the latter is occasionally obliged to rigidify my arguments out of pedagogical considerations" (157, my emphasis). Habermas has overlooked the context and purpose of the reinscription, and Derrida clearly believes that he should not have done so.

The example is interesting, because here Derrida seems in main to be a champion of receptivity against unbridled creativity. But in the same text Derrida points out that the "doubling commentary" or "paraphrase" (that would be the utterance of pure receptivity) "is already an interpretation" and that this interpretation imposes "conventions that are henceforth dominant" (143f). Thus Derrida can state - as part of his interpretation of Searle - that Searle is deeply indebted to Husserl "whether he knows it, recognizes it, or not" (121). Then again, as Derrida points out, the productive element (he deliberately avoids the word creative) in interpretation signifies neither a creation ex nihilo nor a "rendering explicit" of what is already implicit in the text (148). 
creative strategy of interpretation." "By no means. I picked up the word you are referring to in the discourse of my audience. I read it, but in another text." And so on.

The terms "questioning", "interrogating" and "resisting" are popular enough in theoretical discourse. That any position should be subjected ("opened up") to critique is a commonplace. ${ }^{37}$ I would rather like to have "gainsaying" mean something slightly different. Etymologically the "gain" of the term is related to the word for "meeting" (as in German begegnen). When I gainsay an interpretation, I try to meet it, or rather, to meet the persons who placed it in the field of human interaction. ${ }^{38}$ The mode of the meeting may indeed involve questioning or resisting, but it may also involve "meeting halfway" or "meeting up with". In extreme cases gainsaying becomes saying again and not against. In gainsaying one may, in two senses of the phrase, meet one's match. My conception of gainsaying thus refuses to solidify the situation of "interrogation", not only because the interrogator can become the interrogated, but also because in the practice of gainsaying interrogation can be halted, even though further gainsaying remains possible in theory. Indeed, when successive acts of resistance have led to a position in which I am standing right up against my interlocutor, I can resist no more, because the "against" has become "with".

The logic of gainsaying applies to situated, temporal beings - to you and me - and not to the atemporal, disembodied ideal theorist. Since, however, we are not this ideal construct, our theorizing does not remove us beyond the reach of gainsaying. Theorizing is indeed a particular mode of interpretation (reading, reinscription) with a particular focus and purpose, but it is not one that is methodologically privileged. Recent theory has proclaimed time and again, implicitly and explicitly, that it is able to describe "the interpretive conventions" that constitute "the "intelligibility of texts" (or something similar; see Culler 1981:47-79 for this particular version) in a way that bypasses the hazards and potential errors that attend the reading of texts. Undoubtedly, most theorists bring considerable intelligence and years of training and experience to bear on their work, but so do others who offer interpretations of texts instead of interpretations of interpretation. Both projects stand or fall by the same criteria - criteria that may be gainsaid.

In Stanley Fish's version of this, my criteria (inherited from my "interpretive community") constitute the truth for me (Fish 1980:365), while the criteria proposed by those who gainsay me necessarily appear as silly and unreasonable. One further insight is, however, granted to the "metacritical" theorist: the insight that all criteria alike lack foundations. What Fish does not seem to consider is what is commonly called doubt and what I would call the desire to be gainsaid. Certainly, I stumble on as best I can, that is, using what abilities I have and applying the criteria that appear most appropriate to me. I am reasonably (but not absolutely) certain that some interpretations are better than others ${ }^{39}$, and I am fairly (but far from entirely) sure that I can usually tell the difference. In one case I would argue vigorously; in the other I would yield more easily to vigorous counterarguments.

When it came to assessing the interpretations of the Bible study groups, my doubts often reached a still higher level. Certainly, I thought some of the "interpretations" were simply

37. The danger is that a one-sided, puritanical insistence on critique, disruption, resistance and destabilizing can make dialogue seem "impossible or even unethical" (Steele 1997:30). Steele describes this danger (particularly in poststructural theory) well (1997:27-42) and his suggestion that we should add "first- / secondperson accounts" to the "third-person accounts" of theory (1997:8 and passim) deserves attention.

38. Obviously the individual author is among these persons, but there is no need to insist on a unified and centred author, thus the plural.

39. See, for instance, Derrida (1988:46), who does not mince words on this matter. 
wrong, but on the whole I remain far from certain that I was able to deal with the "texts" before me in an adequate way. Descriptions, surely, are never "pure", but always assume an evaluative framework (cf Taylor 1989:3-19). (Note the consequences of denying this.) Nevertheless, when I had to describe (evaluate, interpret) the interaction in the groups, my frameworks could not anchor my description sufficiently to eliminate my own doubts about what I wrote. To what extent could I capture the "thickness" of the events and to what extent was I simply being thick? My reliance on noted "theorists" in this article and my criticism of many of them signal my scepticism about the ability of theory to offer a more robust evaluative framework. This still leaves me with the desire to be gainsaid. Where in the design of the project is the space for gainsaying? The scholarly debate on "the interpretation of the Bible" seems isolated from the vigorous interpretative debates that we witnessed. This is a comment not on the adequacy of any particular interpretation or any model of interpretation, but on the ethics of interpretation - our interpretation. 


\section{BIBLIOGRAPHY}

Abrams, MH 1991. Doing Things with Texts. New York / London: Norton.

Austin, JL 1975. How to Do Things with Words ( $2^{\text {nd }}$ ed). Oxford / New York: Oxford University Press.

Benhabib, S 1999. "Feminism and the Question of Postmodernism." In A Elliott (ed), The Blackwell Reader in Contemporary Social Theory, 351-362. Oxford: Blackwell.

Bennett, A 1995. "Introduction." In A Bennet (ed), On Readers and Reading, 1-19. London / New York: Longman.

The Bible and Culture Collective ${ }^{40}$ 1995. The Postmodern Bible. New Haven / London: Yale University Press.

Bloom, H 1975. A Map of Misreading. New York: Oxford University Press.

Bloom, H 2000. How to Read and Why. London: Fourth Estate.

Brooks, C 1968. The Well Wrought Urn: Studies in the Structure of Poetry. London: Methuen.

Burke, K 1935. Permanence and Change. New York: New Republic

Burke, K 1952. A Grammar of Motives. New York: Prentice Hall.

Burke, K 1966. Language as Symbolic Action: Essays on Life, Literature and Method. Berkeley / Los Angeles: University of California Press.

Burke, K 1970. The Rhetoric of Religion: Studies in Logology. Berkeley / Los Angeles: University of California Press.

Culler, J 1981. The Pursuit of Signs: Semiotics, Literature, Deconstruction. London: Routledge \& Kegan Paul.

Culler, J 1983. On Deconstruction: Theory and Criticism after Structuralism. London / Melbourne: Routledge \& Kegan Paul.

De Man, P 1979. Allegories of Reading: Figural language in Rousseau, Nietzsche, Rilke and Proust. New Haven / London: Yale University Press.

Derrida, J 1988. Limited Inc (translated by S Weber and J Mehlman), Evanston: Northwestern University Press.

Derrida, J 1992. Acts of Literature (articles by J Derrida translated and edited by D Attridge). New York / London: Routledge.

Dimock, W-C, 1995. "Feminism, New Historicism and the Reader." In A Bennet (ed), On Readers and Reading, 112-131. London / New York: Longman.

Docherty, T 1987. On Modern Authority. Briighton / New York: Harvester / St Martin's.

Eagleton, T 1991. Ideology: An Introduction. London / New York: Verso.

Earnshaw, S 1996. The Direction of Literary Theory. London: Macmillan.

Felperin, H 1985. Beyond Deconstruction: The Uses and Abuses of Literary Theory. Oxford: Clarendon.

Fish, S 1980. Is There a Text in This Class?: The Authority of Interpretive Communities. Cambridge, Mass. / London: Harvard University Press.

Fish, S 1989. Doing What Comes Naturally. Durham / London: Duke University Press.

Kant, I 1991. Groundwork of the Metaphysics of Morals (translated and analysed by HJ Patton). London / New York: Routledge.

40. The collective comprises George Aichele, Fred W Burnett, Elizabeth A Castelli, Robert M Fowler, David Jobling, Stephen D Moore, Gary A Phillips. Tina Pippin, Regina M Schwartz and Wilhelm Wuellner. 
LaCapra, D 1989. Soundings in Critical Theory. Ithaca / London: Cornell University Press. Michaels, WB 1980. "The Interpreter's Self: Peirce on the Cartesian 'Subject'." In JP Tompkins ed) Reader-Response Criticism: From Formalism to Post-Structuralism, 185-200. Baltimore / London: Johns Hopkins University Press.

Miller, JH 1987. The Ethics of Reading. New York: Columbia University Press.

Newton, KM 1990. Interpreting the Text. London: Harvester Wheatsheaf.

Righter, W 1994. The Myth of Theory. Cambridge: Cambridge University Press.

Schmidt, H \& Schischkopf, G 1965. Philosophische Wörterbuch. Stuttgart: Kröner.

Scholes, R 1985. Textual Power: Literary Theory and the Teaching of English. New Haven / London: Yale University Press.

Scholes, R 1989. Protocols of Reading. New Haven / London: Yale University Press.

Schweickart, PP 1995. "Reading Ourselves: Towards a Feminist Theory of Reading." In A Bennet (ed), On Readers and Reading, 66-93. London / New York: Longman.

Seitz, JE 1992. “A Rhetoric of Reading." In R Andrews (ed), Rebirth of Rhetoric, 141-155. London / New York: Routledge.

Smit, DJ 1990a. "The Ethics of Interpretation: New Voices from the USA." Scriptura 33, 16-28.

Smit, DJ 1990b. "The Ethics of Interpretation: - and South Africa". ." Scriptura 33, 16-28.

Steele, M 1997. Theorizing Textual Subjects. Cambridge: Cambridge University Press.

Taylor, C 1989. Sources of the Self: The Making of the Modern Identity. Cambridge: Cambridge University Press.

Tompkins, JP 1980. “An Introduction to Reader-Response Criticism”. In JP Tompkins (ed), Reader-Response Criticism: From Formalism to Post-Structuralism, ix-xxvi. Baltimore / London: Johns Hopkins University Press.

Watson, F 1994. Text, Church and World: Biblical Interpretation in Theological Perspective. Edinburgh: T \& T Clarke.

Webster, R 1990. Studying Literary Theory: An Introduction. New York / London: Edward Arnold. 